\title{
Overexpression of the Histone Dimethyltransferase G9a in Nucleus Accumbens Shell Increases Cocaine Self- Administration, Stress-Induced Reinstatement, and Anxiety
}

\author{
Ethan M. Anderson, ${ }^{1}$ Erin B. Larson, ${ }^{1}$ DDaniel Guzman, ${ }^{1}$ Anne Marie Wissman, ${ }^{1}$ Rachael L. Neve, ${ }^{2}{ }^{\circ}$ Eric J. Nestler, ${ }^{3}$ \\ and $\odot$ David W. Self ${ }^{1}$ \\ ${ }^{1}$ Department of Psychiatry, The Seay Center for Basic and Applied Research in Psychiatric Illness, University of Texas Southwestern Medical Center, Dallas, \\ Texas, 75390, ${ }^{2}$ Viral Gene Transfer Core, Department of Brain and Cognitive Sciences, McGovern Institute for Brain Research, Massachusetts Institute of \\ Technology, Cambridge, Massachusetts 02139, and 3Icahn School of Medicine at Mount Sinai, Department of Neuroscience, New York, New York 10029
}

Repeated exposure to cocaine induces lasting epigenetic changes in neurons that promote the development and persistence of addiction. One epigenetic alteration involves reductions in levels of the histone dimethyltransferase G9a in nucleus accumbens (NAc) after chronic cocaine administration. This reduction in G9a may enhance cocaine reward because overexpressing G9a in the NAc decreases cocaineconditioned place preference. Therefore, we hypothesized that HSV-mediated G9a overexpression in the NAc shell (NAcSh) would attenuate cocaine self-administration (SA) and cocaine-seeking behavior. Instead, we found that G9a overexpression, and the resulting increase in histone 3 lysine 9 dimethylation ( $\mathrm{H} 3 \mathrm{~K} 9 \mathrm{me}$ ), increases sensitivity to cocaine reinforcement and enhances motivation for cocaine in self-administering male rats. Moreover, when G9a overexpression is limited to the initial $15 \mathrm{~d}$ of cocaine SA training, it produces an enduring postexpression enhancement in cocaine SA and prolonged (over 5 weeks) increases in reinstatement of cocaine seeking induced by foot-shock stress, but in the absence of continued global elevations in H3K9me2. The increase in stress-induced reinstatement is paralleled by heightened anxiety measures, suggesting that countering the cocaine-induced decreases in endogenous G9a with ectopic G9a overexpression leads to lasting anxiogenic effects. Finally, we found an enduring reduction in phosphorylated cAMP-response element binding protein levels in the NAcSh that could account for the increased anxiety. These data demonstrate a novel role for G9a in promoting comorbid cocaine addiction and anxiety and suggest that increased epigenetic repression of transcription through H3K9 during cocaine use can have long-lasting and unexpected negative consequences on behavior.

Key words: accumbens; addiction; anxiety; cocaine; G9a; H3K9

Significance Statement

Cocaine addiction is a neuropsychiatric disorder that is detrimental to society and currently has no effective treatments. The difficulty in treating drug addiction is compounded by the high comorbidity with other psychiatric illnesses, including anxiety disorders. Here, we demonstrate that G9a, an epigenetic repressor of gene expression, acting in the nucleus accumbens, a brain reward region, is capable of increasing both addiction- and anxiety-like behaviors in rats. These findings are intriguing because repeated cocaine exposure decreases G9a in this region and thereby enhances expression of certain addiction-promoting genes. However, our results suggest that countering this cocaine-induced decrease in G9a activity actually exacerbates addiction and sensitivity to relapse under stressful situations.

\section{Introduction}

Cocaine addiction is a neuropsychiatric disorder that is detrimental to society and currently has no effective treatments (Mar-

Received June 14, 2017; revised Nov. 3, 2017; accepted Nov. 27, 2017

Author contributions: E.M.A., R.L.N., E.J.N., and D.W.S. designed research; E.M.A., E.B.L., D.G., A.M.W., R.L.N., and D.W.S. performed research; R.L.N. and E.J.N. contributed unpublished reagents/analytic tools; E.M.A. analyzed data; E.M.A. and D.W.S. wrote the paper.

This work was supported by the National Institutes of Health (Grants T32 DA 007290 and P01 DA 08227). We thank Joyce Chemplanikal for assistance with the cocaine SA experiments and Shari Birnbaum for assistance with the EPM and open-field behavioral assays. tell et al., 2005; Dennis et al., 2007; Johnson et al., 2013). The difficulty in treating addicted patients is compounded by the high comorbidity of addiction with other psychiatric syndromes primarily involving mood and anxiety disorders (Back and Brady,

\footnotetext{
The authors declare no competing financial interests.
}

Correspondence should be addressed to David W. Self, Department of Psychiatry, The Seay Center for Basic and Applied Research in Psychiatric IIIness, UT Southwestern Medical Center, 5323 Harry Hines Boulevard, Dallas, Texas, 75390-9070. E-mail: David.Self@UTSouthwestern.edu.

DOI:10.1523/JNEUROSCI.1657-17.2017

Copyright $\odot 2018$ the authors $\quad 0270-6474 / 18 / 380803-11 \$ 15.00 / 0$ 
2008; Vorspan et al., 2015). In some instances, premorbid anxiety could convey vulnerability to cocaine addiction. In other cases, the neurobiological consequences of chronic cocaine use could contribute to both anxiety and drug-seeking behavior. Therefore, it is important to understand the role of certain drug-induced neuroadaptations in multiple behavioral changes to fully appreciate their impact on drug addiction.

Repeated exposure to cocaine induces lasting epigenetic changes in the brain by modifying the chromatin structure of DNA via histone acetylation, phosphorylation, and/or methylation (Robison and Nestler, 2011). For instance, recent work has shown that histone 3 lysine 9 dimethylation (H3K9me2) is substantially reduced in the nucleus accumbens (NAc) after chronic cocaine self-administration (SA) due to decreased levels of the histone dimethyltransferase G9a, which normally acts to suppress transcription (Maze et al., 2010). A subsequent study found that G9a is a negative regulator of brain-derived neurotrophic factor (BDNF) signaling through tyrosine receptor kinase $\mathrm{B}$ (TrkB), which activates the transcription factor cAMP-response element binding protein (CREB), and these effects could convey resilience to negative mood effects in social defeat (Covington et al., 2011). Therefore, reduced G9a followed by increased BDNF-TrkB-CREB signaling in cocaine addiction could contribute to depressive-like behavior (Carlezon et al., 2005) and a similar epigenetic interaction between reduced G9a activity and increased BDNF-TrkB-CREB activity could exacerbate the negative reinforcing properties of cocaine in self-administering rats (Larson et al., 2011).

These findings led to the hypothesis that increases in G9a levels in the NAc would counteract proaddiction processes and reduce cocaine SA and a propensity for relapse. In support of this hypothesis, previous work found that overexpression of G9a in the NAc decreases cocaine conditioned place preference (CPP), whereas localized inducible knock-out of G9a in floxed G9a mice enhances cocaine CPP (Maze et al., 2010). Therefore, G9a overexpression could be a potential mechanism to reduce the rewarding effects of cocaine, possibly through suppression of BDNF-TrkB-CREB signaling (Covington et al., 2011). However, instead, we discovered that transient G9a overexpression in NAc shell (NAcSh) increases in the motivation for cocaine in selfadministering rats and facilitates the ability of stress to trigger relapse during cocaine abstinence long after G9a levels return to normal. These behaviors may relate to an increase in anxiety, potentially due to a paradoxical and lasting downregulation of phosphorylated CREB levels in the NAcSh. The findings suggest that G9a-mediated repression of gene transcription during cocaine use can lead to surprising addiction-promoting and anxiogenic influences.

\section{Materials and Methods}

Animal use and care. Adult male Sprague Dawley rats (Charles River Laboratories) initially weighing $250-300 \mathrm{~g}$ were singly housed in a climate-controlled environment $\left(21^{\circ} \mathrm{C}\right)$ on a $12 \mathrm{~h}$ light/dark cycle (lights on at 6:00 A.M.). All animals were habituated to the housing environment for at least $7 \mathrm{~d}$ before use in experiments and had ad libitum access to food and water except when rats received operant training with sucrose pellets. All experiments were performed during the light cycle. These studies were approved by the University of Texas Southwestern (UTSW) institutional Animal Care and Use Committee and facilities are accredited by the American Association for the Accreditation of Laboratory Animal Care (AAALAC). All procedures were conducted in accordance with the guidelines established by the National Institutes of Health and the National Research Council.

Vector construction. The HSV-GFP and HSV-G9a vectors were constructed as described previously (Neve et al., 2005). For the HSV-G9a vector, transgene expression of G9a was driven by an IE 4/5 promoter and GFP was coexpressed in the same vector by a CMV promoter. For the HSV-GFP vector, GFP was expressed by a CMV promoter.

G9a and GFP in HeLa cell culture. HeLa cells were grown in 12-well plates in Dulbecco's modified eagle medium (DMEM) supplemented with 10\% FBS and penicillin/streptavidin. Each well was infected with $0.1 \mu \mathrm{l}$ of HSV virus in $0.5 \mathrm{ml}$ of DMEM. One day after HSV infection, cells were imaged with a Nikon Inverted Microscope using a Leica DFC450C Cooled Color 5MP Camera. Images were taken in both bright field and with a Cy2 filter to confirm GFP expression before harvesting. Images were processed and merged with ImageJ software. Cells were harvested by first rinsing with $4^{\circ} \mathrm{C}$ PBS, followed by the addition of $100-200 \mu l$ of homogenization buffer, scraping and pipetting into a tube for immediate sonication before freezing on dry ice. Cell culture experiments were run multiple times, but one representative image was selected for the figures.

Western blotting. Blots were run according to the methods in Edwards et al. (2007a) except where noted. Briefly, samples were quantified with a Lowry assay and $20 \mu \mathrm{g}$ of protein was electrophoresed on $7.5 \%$ polyacrylamide gels, transferred to PVDF membranes, blocked in 5\% BSA or 5\% dry milk in TTBS for $1-2 \mathrm{~h}$ before addition of primary antibodies for overnight incubation at $4^{\circ} \mathrm{C}$. The following day, after $310 \mathrm{~min}$ washes in buffer, secondary antibodies were added for at least $1 \mathrm{~h}$ in TTBS. After 3 more 10 min washes, blots were coated with ECL 2 (Thermo Pierce) and exposed to film (Kodak). Primary antibodies were as follows: anti-G9a/ EHMT2 (RRID:AB_731483, Abcam, catalog \#ab40542, rabbit), anti-histone H3 (RRID:AB_331563, Cell Signaling Technology, catalog \#9715S, rabbit), anti-H3K9me2 (RRID:AB_449854, Abcam, catalog \#ab1220, mouse), antiphospho-CREB-Ser133 (RRID:AB_331275, Cell Signaling Technology, catalog \#9196L, mouse), anti-CREB (RRID:AB_331277, Cell Signaling Technology, catalog \#9197, rabbit), and anti- $\beta$-tubulin III (RRID: AB_2313564, Aves, catalog \#TUJ, chicken). Secondary antibodies were as follows: anti-rabbit (RRID:AB_11125142, Bio-Rad, catalog \#170-6515) or anti-mouse HRP (RRID:AB_11125547, Bio-Rad, catalog \#170-6515). Blots were first probed for anti-H3K9 or anti-phospho-CREB, stripped with Restore buffer (Thermo Fisher Scientific), reblocked, and reprobed with anti-H3 or anti-CREB, respectively. Phosphoprotein and total protein levels were analyzed with ImageJ software.

Rat stereotaxic cannulation. For in vivo HSV characterization and behavioral experiments, rats were anesthetized (ketamine/xylazine, 100/10 $\mathrm{mg} / \mathrm{kg}$, i.p.) and bilateral guide cannulae were implanted above the NAcSh (AP $+1.7 \mathrm{~mm}, \mathrm{ML}-0.75 \mathrm{~mm}, \mathrm{DV}-5.7 \mathrm{~mm}$ ventral to dura) fixed in place with skull screws and dental cement. After recovery for at least $5 \mathrm{~d}, 2.0 \mu \mathrm{l}$ of HSV vector was infused bilaterally for $10 \mathrm{~min}$ using infusion needles that projected $1.0 \mathrm{~mm}$ below the guide cannula $(-6.7 \mathrm{~mm}$ ventral to the dura). Tissue was then harvested after $3 \mathrm{~d}$ for peak HSV expression by taking half-moon punches of NAc shell from chilled 1-mm-thick coronal brain slices $(\sim+1.7 \mathrm{~mm}$ anterior to bregma) as described previously (Edwards et al., 2011). For the in vivo NAcSh HSV Western blot characterization shown in Figure 1, one side of the brain was infused with HSV-G9a and the other with HSV-GFP to allow for paired analysis. Samples were immediately frozen on dry ice before homogenizing and running on blots as described above. HSV-mediated expression was also compared in rats receiving either 1 or 3 weekly spaced HSV-GFP infusions unilaterally, as shown in Figure 4. Rats were perfused $3 \mathrm{~d}$ after the HSV infusions.

Immunohistochemical labeling of G9a/GFP, cresyl violet staining, and confocal microscopy. In cannulated rats, HSV-GFP or HSV-G9a was infused as described above. Three days later, rats were injected with chloral hydrate $(300-600 \mathrm{mg} / \mathrm{kg}$, i.p.) and perfused with $1 \%$ paraformaldehyde in PBS for 1-2 min, followed by $4 \%$ paraformaldehyde for an additional $10 \mathrm{~min}$. The extracted brains were stored for at least $24 \mathrm{~h}$ in paraformaldehyde before sectioning on a Vibratome (75-100 $\mu \mathrm{m}$ slices) and slices were stored in PBS with sodium azide. Sections were blocked in buffer (3\% normal donkey serum and $0.1 \%$ Triton X-100 in PBS) for $1 \mathrm{~h}$, followed by incubation with primary antibodies against GFP (RRID: AB_10000240, Aves Laboratories, catalog \#GFP-1020, chicken, 1:5000, ) colabeled with G9a/EHMT2 (Abcam, catalog \#ab40542, rabbit) overnight at $4^{\circ} \mathrm{C}$. After three 10 min washes, buffer with secondary antibodies 
was added: Cy3 donkey anti-rabbit (RRID:AB_2307443, Jackson Laboratories, catalog \#711-165-152, 1:1000), Alexa Fluor 488 donkey anti-chicken (RRID:AB_2340375, Jackson Laboratories, catalog \#703545-155, 1:200), and Fluorescein Anti-chicken (RRID:AB_2313516, Aves Laboratories, catalog \#F-1005, 1:1000). After three additional washes with buffer, the sections were mounted on slides in Vectashield (Vector Laboratories), coverslipped, and sealed with a nitrocellulose lacquer. All images were obtained with a Zeiss LSM 510 confocal microscope. $Z$-stacks were taken at $0.38 \mu \mathrm{m}$ intervals. Images were processed using ImageJ software. Cresyl violet and anti-GFP fluorescence were compared after one or three unilateral HSV infusions in perfused brains cryoprotected in $30 \%$ sucrose and $40 \mu \mathrm{m}$ slices collected on cryostat and processed for anti-GFP as above. Other slices were mounted and then dehydrated via ethanol and citrisolv washes before soaking in $0.1 \%$ cresyl violet acetate. Slides were dried in ethanol, coverslipped, and visualized at $4 \times$ magnification.

Cocaine SA: Experiment 1. A timeline of this experiment is shown in Figure $2 a$. For this first set of cocaine SA experiments, food-restricted rats were initially trained to lever press for vanilla-flavored sucrose pellets (BioServ, catalog \#F0021, $45 \mathrm{mg}$ ) in operant chambers (Med Associates) on a fixed ratio 1 (FR1) reinforcement schedule until they achieved 100 pellets in a $1 \mathrm{~h}$ session (1-3 d). After lever training, rats were fed ad libitum at least $48 \mathrm{~h}$ before surgical implantation of both bilateral guide cannulae and chronic indwelling jugular catheter as described previously (Edwards et al., 2007b). Catheters were flushed daily with $0.2 \mathrm{ml}$ of heparinized bacteriostatic saline containing gentamycin sulfate $(0.33 \mathrm{mg} / \mathrm{ml})$ to maintain patency. After at least $5 \mathrm{~d}$ of recovery, rats were placed in operant chambers with their catheters attached to syringe pumps. A single leverpress response delivered $0.5 \mathrm{mg} / \mathrm{kg}$ cocaine hydrochloride in $50 \mu \mathrm{l}$ of sterile saline over $2.5 \mathrm{~s}$ concurrent with a cue light above the active lever. House lights were off during the injection and for an additional $12.5 \mathrm{~s}$ timeout period. SA training sessions lasted $3 \mathrm{~h} / \mathrm{d}$ for $5 \mathrm{~d} /$ week over 3-4 weeks (15-20 sessions) until criteria for stable responding was obtained $(<15 \%$ variance over the final $3 \mathrm{~d}$ of SA training). The FR requirement was incrementally increased first to FR 3 and then to FR 5 by the end of the 3- to 4-week training period.

After cocaine SA training and stabilization, rats received HSV infusions before both dose-response on FR and progressive ratio (PR) SA tests as described previously (Larson et al., 2011) and outlined in Figure $2 a$. Rats were tested in a within-session cocaine SA dose-response test before, during, and after transient (1-5 d) HSV expression (Neve et al., 2005). Each within-session dose-response test began with a $30 \mathrm{~min}$ loading phase with access to the training dose $(0.5 \mathrm{mg} / \mathrm{kg} /$ injection $)$, followed by 5 consecutive $30 \mathrm{~min}$ components when descending injections doses were available $(1.0,0.3,0.1,0.03$, and $0 \mathrm{mg} / \mathrm{kg}$, i.v.). Cocaine SA doseresponse data were averaged across $2 \mathrm{~d}$ before HSV (days 4-5); baseline measures in the viral treatment groups were counterbalanced based on baseline SA and dose-response responding. The third day after HSV infusion was used for behavioral analysis during peak expression, whereas post-HSV data were averaged across days $4-5$ during the following week after HSV (11-12 d after initial HSV infusion when viral expression is absent; Neve et al., 2005). After dose-response testing on the FR5 schedule, cocaine SA restabilized at the training dose for an additional week. Next, the rats received a second HSV infusion with the same vector for analysis of cocaine SA on a PR reinforcement schedule. Here, the ratio of lever presses/cocaine injection increased progressively for each successive injection in an exponential fashion $(1,2,4,6,9,12,15,20 \ldots)$ (Richardson and Roberts, 1996) and breakpoints were defined as the last completed ratio before a $1 \mathrm{~h}$ period when no further injections were earned. Cocaine SA on the PR schedule was conducted with 2 injection doses $(0.25$ and $0.75 \mathrm{mg} / \mathrm{kg} /$ injection) in counterbalanced order, each tested in two consecutive sessions. The second test day at each dose was used for analysis. At the end of both the dose-response and PR testing phases, catheter patency was confirmed by brief induction of anesthesia with intravenous methohexital injection. One HSV-G9a animal lost catheter patency and did not complete PR testing after the second HSV infusion.

After 2 weeks of abstinence after the PR testing, rats were tested in extinction and reinstatement according to previously published methods
(Larson et al., 2011). Briefly, rats were placed into the same operant chambers but under extinction conditions: the levers and house light were present, but lever pressing did not result in cue presentation, houselight deactivation, pump activation (i.e., sound cues), or cocaine injections. After $5 \mathrm{~d}$ of $3 \mathrm{~h}$ extinction sessions, there were $5 \mathrm{~d}$ of reinstatement testing. First, cue-induced reinstatement was tested over a $1 \mathrm{~h}$ period after $2 \mathrm{~h}$ of additional extinction conditions; drug-paired cue lights and pump sounds were presented noncontingently every $2 \mathrm{~min}$ for the $1 \mathrm{~h}$ test. Next, reinstatement induced by cocaine-priming injections was tested with cocaine $(0,5$, or $15 \mathrm{mg} / \mathrm{kg}$ cocaine, i.p.) over 3 consecutive days in counterbalanced order. Finally, reinstatement induced by footshock stress was measured for a $1 \mathrm{~h}$ period after $30 \mathrm{~min}$ of random interval shocks $(0.8 \mathrm{mV} / 0.5 \mathrm{~s})$ at an average interval of $30 \mathrm{~s}$. Rats that did not reinstate (i.e., 0 lever responses) in particular reinstatement test were removed from the specific analysis for that test, but not necessarily from other tests. For example, a rat that lever pressed 0 times in the cue reinstatement test was removed from the cue reinstatement analysis, but not cocaine or stress reinstatement if responding 1 or more times, leading to different group numbers in tests shown in Figures 3 and 5. After Experiment 1, rats were injected with chloral hydrate $(400 \mathrm{mg} / \mathrm{kg}$, i.p. $)$ and cresyl violet $(0.5 \mu \mathrm{l})$ was infused bilaterally into the guide cannula. Brains were removed and 1-mm-thick slices were collected to identify the infusion sites using a brain atlas (Paxinos and Watson, 1997). Animals with infusions outside of the NAcSh were excluded from the study. One HSVG9a animal lost catheter patency and did not complete PR testing after the second HSV infusion.

Anxiety-like symptoms during cocaine SA. Before and after each cocaine SA session, animals were examined and any unusual behaviors or conditions were each recorded as unitary measures. Specific anxietylike symptoms included diarrhea-like fecal material, porphyrin staining, self-induced scratches, or erratic behavior (attempting to jump out of the SA box after the session, biting, or twisting up in the SA chamber tubing; Harkness and Ridgway, 1980; Marczynski and Urbancic, 1988; Yuan and Devine, 2016). The average numbers of symptoms per week per animal were recorded, although the experimenters were not blinded to HSV group status.

Cocaine SA: Experiment 2. To test the enduring effects of G9a overexpression limited to the initial acquisition/training phase of cocaine SA, animals were subjected to similar SA procedures except where noted below and shown as a timeline in Figure $4 a$. Here, rats received an initial HSV infusion $1 \mathrm{~d}$ before 5 consecutive cocaine SA training sessions. This infusion was repeated twice at the beginning of each week for a total of 3 HSV infusions over exactly $15 \mathrm{~d}$ ( $5 \mathrm{~d}$ /week) of cocaine SA similar to previously published studies (Bachtell et al., 2008; Taniguchi et al., 2017). Dose-response testing on FR and PR reinforcement schedules followed for 2 weeks, commencing $8 \mathrm{~d}$ after the final HSV infusion, when expression is no longer evident. After a 2-week abstinence period, extinction and reinstatement tests were performed as described above. One HSVGFP and 1 HSV-G9a animal died during the abstinence period.

Elevated plus maze (EPM). After extinction/reinstatement testing, rats from Experiment 2 were placed in the center of a black Plexiglas EPM (each arm $49 \mathrm{~cm}$ long and $13 \mathrm{~cm}$ wide with two opposite arms closed by $40.5 \mathrm{~cm}$ high walls) elevated $45 \mathrm{~cm}$ in a dimly lit room (lux readings for the closed arms were 10-15 and for open arms were 60-80) and allowed to explore for $5 \mathrm{~min}$. The animals were monitored from above by a video camera connected to a computer running video-tracking software (Ethovision 3.0; Noldus) to determine time spent in the open and closed arms, time spent in the middle, and the number of entries into the open and closed arm. The apparatus was wiped and allowed to dry between rats.

Open-field activity. The next day, rats were placed in the periphery of a novel open-field environment $(74.25 \times 74.25 \mathrm{~cm})$ in a dimly lit room (lux readings were $35-50$ for the periphery and $70-75$ for the center) and allowed to explore for $5 \mathrm{~min}$. The animals were monitored from above by a video camera connected to a computer running video-tracking software (Ethovision 3.0; Noldus) to determine the time, distance moved, and number of entries into two areas: the periphery $(49.25 \mathrm{~cm}$ from the walls) and the center $(25 \mathrm{~cm} \times 25 \mathrm{~cm})$. The open-field arena was wiped 
a

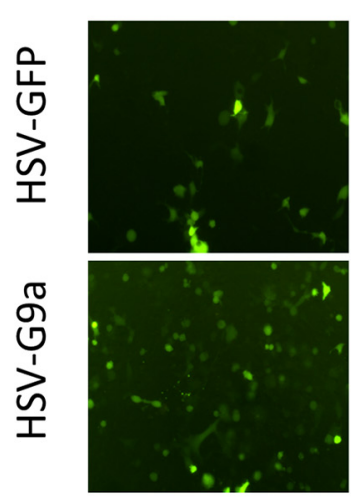

C
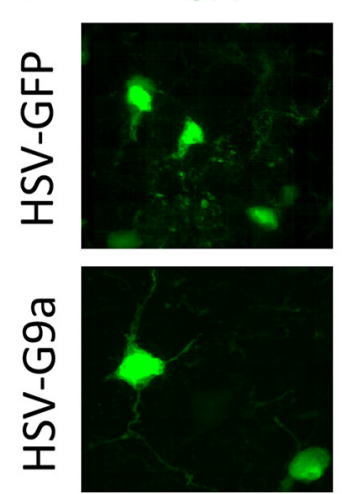

Brightfield

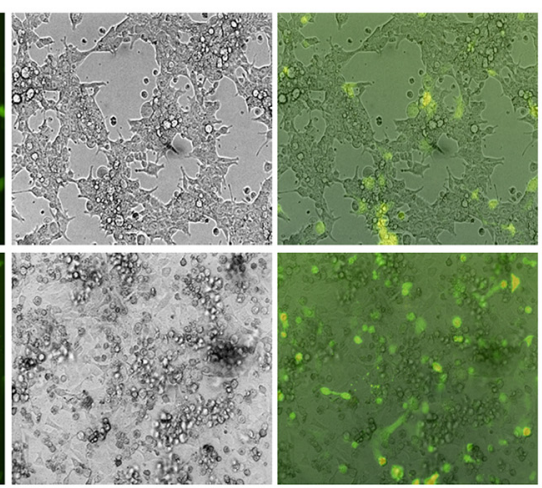

G9a
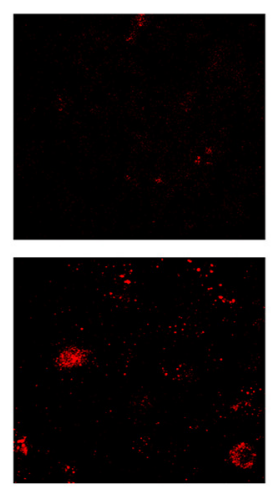

Merge
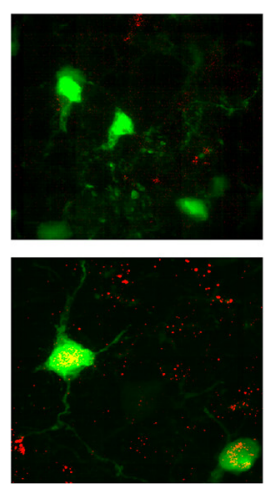

d
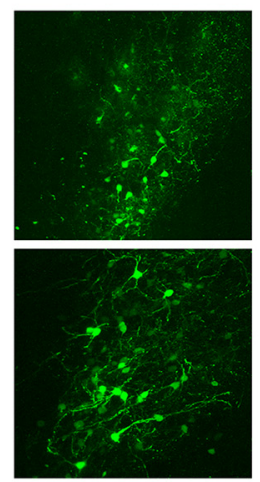

b Expression in HeLa cells
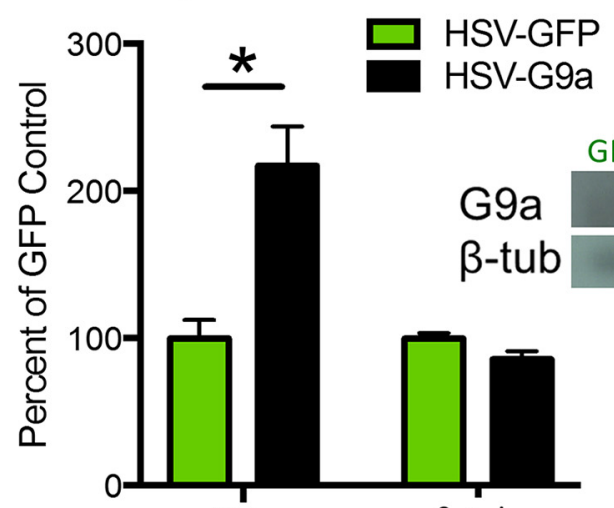

e

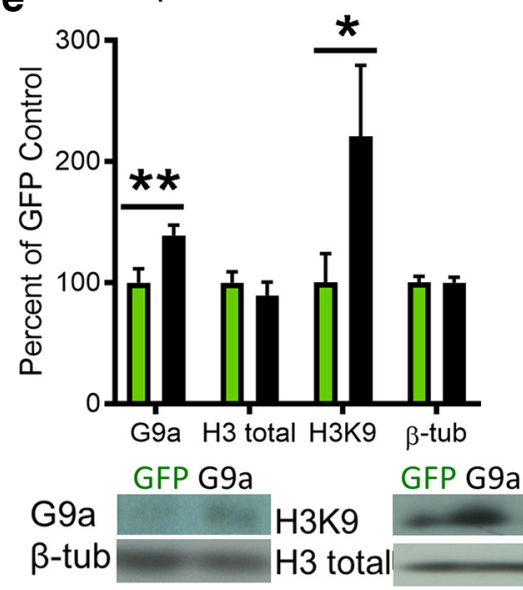

Figure 1. HSV-G9a-mediated G9a overexpression and H3K9me2. $\boldsymbol{a}$, GFP expression in both HSV-G9a- and HSV-GFP-expressing HeLa cells. $\boldsymbol{b}$, Protein levels of G9a and $\beta$-tubulin after HSV infection in vitro (HSV-GFP: $n=4$, HSV-G9a: $n=8$ ). c, $100 \times$ images of NAcSh tissue infected with HSV-GFP or HSV-G9a in vivo and immunolabeled for GFP and G9a. $\boldsymbol{d}$, GFP expression after HSV infection at $20 \times$ magnification. $\boldsymbol{e}$, Protein levels of G9a, Histone H3, H3K9me2, and $\beta$-tubulin in the NACSh $3 \mathrm{~d}$ after HSV expression (HSV-GFP: $n=4$, HSV-G9a: $n=4$ ). Data are expressed as mean \pm SEM. ${ }^{*} p<0.05$ and ${ }^{* *} p<0.01$ compared with HSV-GFP.

and allowed to dry between rats. After completion of Experiment 2, NAcSh tissue was dissected at the cannula tips for Western blot analyses as described above.

Experimental design and statistical analysis. Behavioral data were analyzed with mixed-model repeated-measures two-way ANOVA. Withinsubject factors were time or dose, and between-subject factors were group (HSV-GFP vs HSV-G9a). Differences between vector groups after a significant interaction were compared with least significant difference post hoc tests. $t$ tests were used for comparisons of HSV-GFP and HSVG9a in biochemical analyses of HeLa and in cue and stress-induced reinstatement tests. A paired $t$ test was used to compare HSV-GFP and HSV-G9a after in vivo HSV infusions. An $F$ test was used to compare the variability (SD) of the inter-reinforcement interval in Experiment 2. All statistics were performed with GraphPad Prism software and $p<0.05$ was considered significant. Sample sizes were determined based on previous data from the Self laboratory. Animal numbers for each experiment can be found in the figure legends.

\section{Results}

Competent HSV-mediated expression was first evaluated both in vitro and in vivo. Figure 1, $a$ and $b$, shows that both HSV-GFP and HSV-G9a vectors expressed GFP protein in HeLa cells in vitro, but only HSV-G9a infected cells showed an increase in G9a protein relative to HSV-GFP controls $\left(t_{(10)}=2.942, p=0.0147\right)$, whereas $\beta$-tubulin levels remained unchanged $\left(t_{(10)}=1.749, p=\right.$ 0.1108). After HSV infusions in the NAcSh of rats, prominent increases in G9a immunoreactivity colocalized with GFP in tissue expressing HSV-G9a but not HSV-GFP (Fig. 1c), although both vectors showed similar infection spread at a lower magnification (Fig. 1d). Quantitative Western blot analysis of NAcSh tissue also showed that HSV-G9a increased both G9a levels $\left(t_{(3)}=7.429\right.$, $p=0.0050)$ and $\mathrm{H} 3 \mathrm{~K} 9 \mathrm{me} 2\left(t_{(3)}=3.271, p=0.0467\right)$ compared with HSV-GFP controls, but had no effect on total histone H3 levels $\left(t_{(3)}=0.7409, p=0.5125\right)$ or $\beta$-tubulin protein $\left(t_{(3)}=\right.$ $0.01316, p=0.9903$ ) (Fig. 1e). Together, these findings confirm overexpression of G9a and functional modulation of downstream H3K9me2 in the NAcSh with HSV-G9a infusions.

We tested the hypothesis that G9a overexpression would reduce cocaine SA behaviors in a manner similar to its effects on cocaine CPP (Maze et al., 2010). Before HSV infusion, animals were trained to SA cocaine for at least $15 \mathrm{~d}$, as depicted in Figure $2 a$, and the effects of G9a on cocaine SA behavior were measured in sequential SA tests on FR and PR dose-response reinforcement schedules. Stabilized cocaine SA was counterbalanced across both study groups before HSV infusions (Fig. $2 b$; vector: $F_{(1,16)}=$ $0.01274, p=0.9116$; time: $F_{(14,224)}=4.23, p<0.0001$; interaction: $\left.F_{(14,224)}=1.139, p=0.3248\right)$ and no group differences were apparent in baseline (pre-HSV) SA dose-response curves during within-session testing (Fig. $2 c$; vector: $F_{(1,16)}=0.3013, p=0.5907$; dose: $F_{(4,64)}=59.8, p<0.0001$; interaction: $F_{(4,64)}=0.4576, p=$ 
a

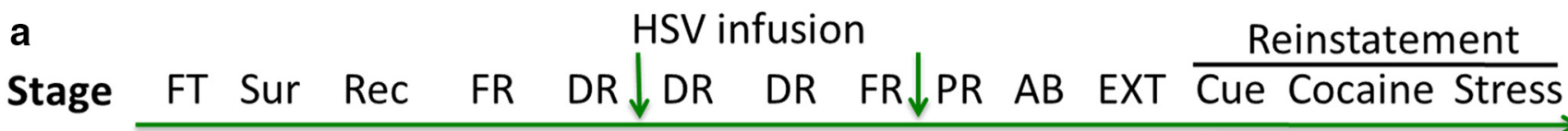

Time 3d 1d 1-2wk 3wk 1wk 1wk 1wk 1wk 4d 2wk1wk 1day 3days 1day

Viral Expression

b

Fixed ratio intake

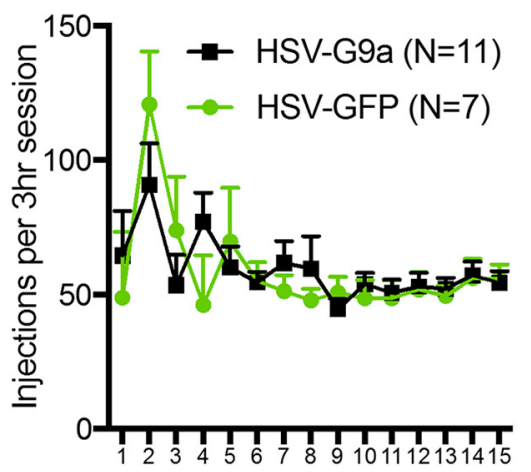

Day of fixed ratio responding

e Post-HSV dose response

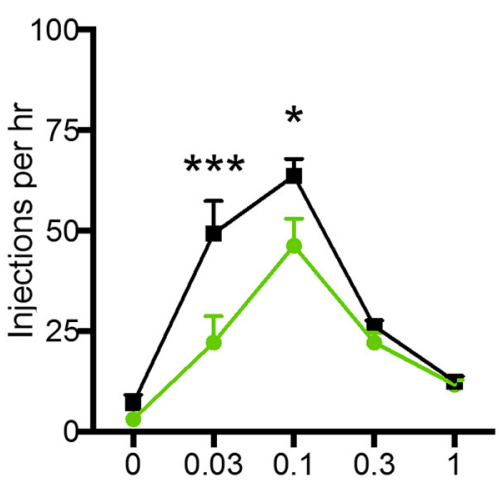

Dose of cocaine $(\mathrm{mg} / \mathrm{kg} / \mathrm{inf})$
C Baseline dose response

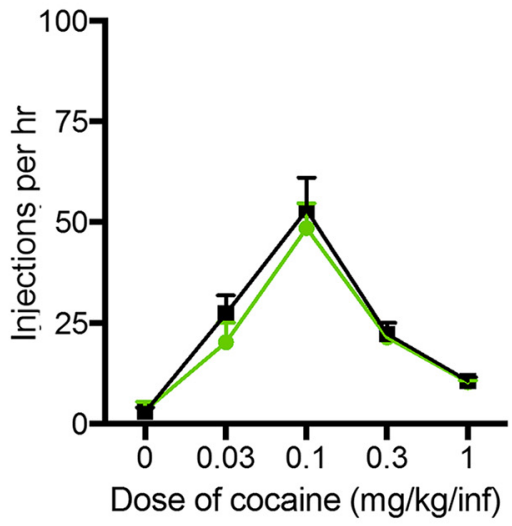

f Re-stabilization Cocaine Intake

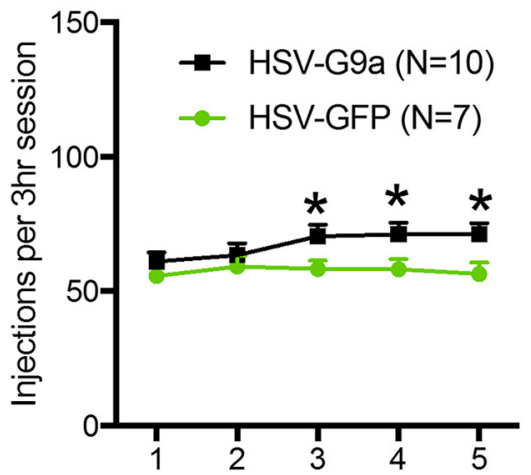

Day of fixed ratio responding d Peak HSV expression

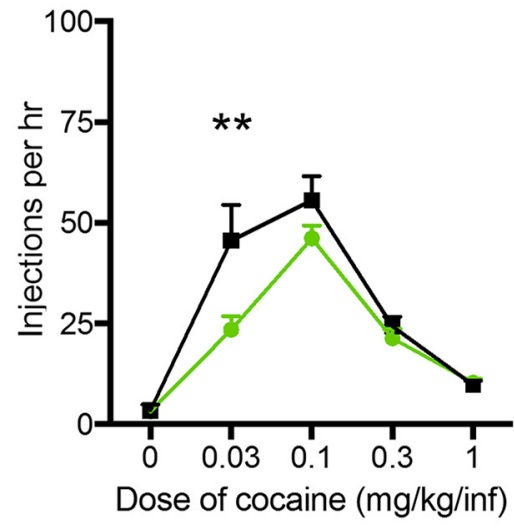

Progressive ratio

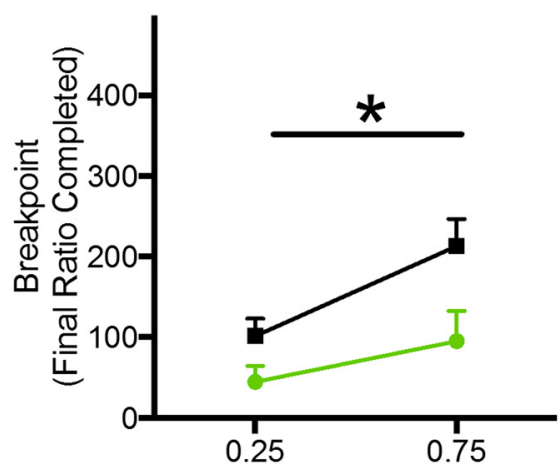

Dose of cocaine (mg/kg/inf)

Figure 2. G9a overexpression increases cocaine SA behaviors. $a$, Experimental time course depicting operant training with food pellets (FT), surgery (Sur), recovery (Rec), and fixed ratio (FR) cocaine SA training, followed by FR dose-response (DR) testing before, during, and after HSV-mediated expression of HSV-GFP or HSV-G9a. A second HSV infusion is given prior cocaine SA testing on a PR reinforcement schedule. Small green arrows represent HSV infusion times after counterbalancing groups for cocaine intake and dose-response; large green arrows represent viral expression periods limited to FR dose-response and progressive ratio testing. Extinction (EXT) and reinstatement tests were performed after a 2-week abstinence period (AB). $\boldsymbol{b}$, Average cocaine reinforcers in study groups during cocaine SA acquisition/stabilization training before HSV infusions. $\boldsymbol{c}$, FR dose-response testing before (c), during (d), and after ( $\boldsymbol{e}$ ) peak HSV-mediated expression of GFP or G9a (HSV-GFP: $n=7$, HSV-G9a: $n=11$ ). $\boldsymbol{f}$, Restabilization of cocaine SA after the first HSV infusion. $\boldsymbol{g}$, Cocaine SA on a PR schedule during GFP or G9a expression after a second HSV infusion. HSV-GFP: $n=7$, HSV-G9a: $n=10$. Data are expressed as mean \pm SEM. ${ }^{*} p<0.05,{ }^{* *} p<0.01$, and ${ }^{* * *} p<0.001$ compared with HSV-GFP.

0.7665). However, $3 \mathrm{~d}$ after intra-NAcSh HSV infusions during peak HSV-mediated expression with this vector (Penrod et al., 2015), animals overexpressing G9a exhibited a, leftward shift in dose sensitivity for maintaining cocaine SA compared with GFPexpressing controls (Fig. $2 d$; vector: $F_{(1,16)}=2.651, p=0.1230$; dose: $F_{(4,64)}=45.07, p<0.0001$; interaction: $F_{(4,64)}=2.731, p=$ $0.0366)$. This effect remained during the following week of doseresponse testing, when HSV expression is no longer evident (Sutton et al., 2003; Barrot et al., 2005), suggesting that G9a overexpression produces lasting increases in sensitivity to cocaine reinforcement in self-administering animals (Fig. $2 e$; vector: $F_{(1,16)}=6.304, p=0.0232$; dose: $F_{(4,64)}=52.98, p<0.0001$; interaction: $\left.F_{(4,64)}=4.237, p=0.0042\right)$. Rats were given an additional week of cocaine SA to restabilize on the training dose and the HSV-G9a group displayed a small but significant escalation in cocaine intake after 3-5 d compared with HSV-GFP controls (Fig. $2 f$, vector: $F_{(1,75)}=14.23 p=0.0003$; time: $F_{(4,75)}=0.8283$, $p=0.5113$; interaction: $\left.F_{(4,75)}=0.6663, p=0.6174\right)$. Rats subsequently received a second intra-NAcSh infusion with the same HSV vector and the degree of effort they would exert to maintain SA behavior was assessed on the PR reinforcement schedule at two cocaine injection doses, both above threshold for maintaining SA behavior in FR dose-response testing. HSV-G9a overexpression in the NAcSh enhanced the motivation for cocaine, as indicated by the highest ratio of lever presses/cocaine injection achieved before animals voluntarily ceased SA behavior (Fig. $2 g$; vector: $F_{(1,15)}=4.935, p=0.0421$; dose: $F_{(1,15)}=31.03, p<0.0001$; interaction: $\left.F_{1,15}=4.300, p=0.0557\right)$. These results indicate that G9a overexpression in the NAcSh increases the sensitivity to, and the motivation for, cocaine SA. 
a

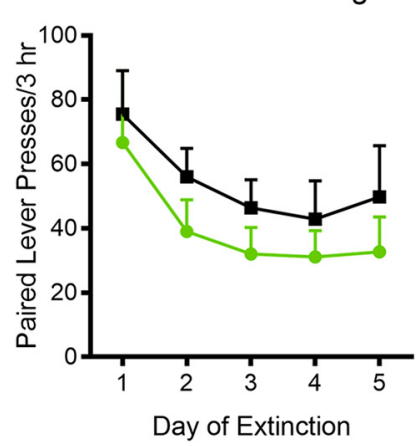

b Cue Reinstatement

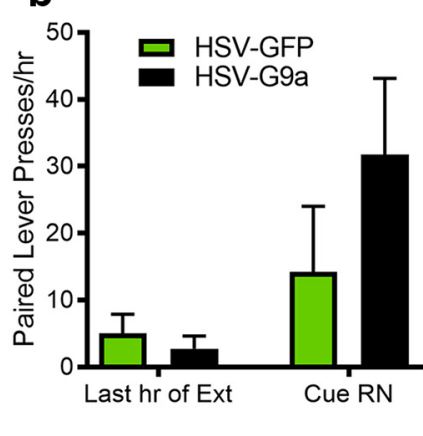

C Cocaine Reinstatement

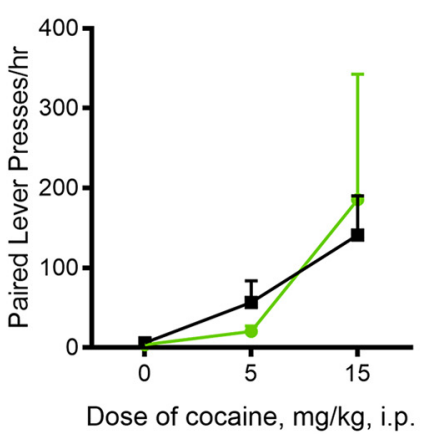

d Stress Reinstatement

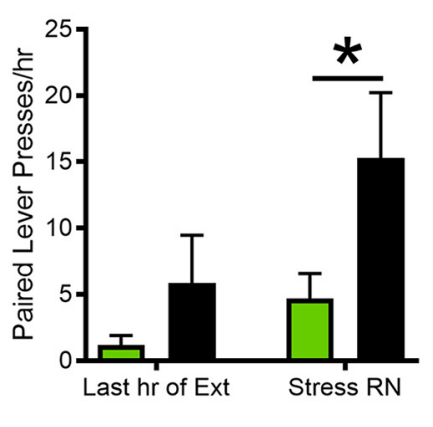

Figure 3. G9a overexpression during prior cocaine SA leads to selective increases in foot-shock stress-induced reinstatement. Shown are paired lever presses over $5 \mathrm{~d}$ of extinction in $3 \mathrm{~h}$ sessions (HSV-GFP: $n=7$, HSV-G9a: $n=10 ; \boldsymbol{a}$ ), after noncontingent light and tone cue presentation (HSV-GFP: $n=6$, HSV-G9a: $n=7 ; \boldsymbol{b}$ ), after intraperitoneal injections of saline or cocaine (HSV-GFP: $n=$ 6, HSV-G9a: $n=9 ; \boldsymbol{c}$ ), or subsequent to intermittent foot shocks for 30 min (HSV-GFP: $n=6$, HSV-G9a: $n=7 ; \boldsymbol{d}$ ). Data are expressed as mean \pm SEM. ${ }^{*} p<0.05$ compared with HSV-GFP.

These HSV viral vectors express their transgenes transiently, with expression declining to undetectable levels after $\sim 5 \mathrm{~d}$ (Sutton et al., 2003; Barrot et al., 2005). Therefore, we tested whether transient overexpression of G9a after 2 HSV infusions (3 weeks apart) during cocaine SA testing would alter the propensity for cocaine-seeking behavior 2-3 weeks after abstinence from cocaine SA. There were no significant differences in nonreinforced drug-paired lever responding during extinction testing in $3 \mathrm{~h}$ sessions over $5 \mathrm{~d}$ in animals receiving prior NAcSh infusions of HSV-GFP or HSV-G9a (Fig. $3 a$, vector: $F_{(1,15)}=1.114, p=$ 0.3078; time: $F_{(4,60)}=3.939, p=0.0066$; interaction: $F_{(4,60)}=$ $0.06447, p=0.9922)$. Similarly, there were no differences in cueinduced reinstatement (Fig. $3 b, t_{(11)}=1.313, p=0.1079,1 \mathrm{GFP}$ and 3 G9a rats did not reinstate) or cocaine-induced reinstatement (Fig. $3 c$, vector: $F_{(1,14)}=0.001323, p=0.9715$; dose: $F_{(2,28)}=4.368$, $p=0.0223$; interaction: $F_{(2,28)}=0.2579, p=0.7746 ; 1 \mathrm{GFP}$ and 1 $\mathrm{G} 9$ a rat did not reinstate). In contrast, the ability of a brief $30 \mathrm{~min}$ period of intermittent foot shocks to reinstate cocaine seeking was increased markedly in animals receiving prior HSV-G9a infusions (Fig. $3 d, t_{(11)}=1.862, p=0.0448,1 \mathrm{GFP}$ and $3 \mathrm{G} 9 \mathrm{a}$ rats did not reinstate), indicating that $\mathrm{HSV}-\mathrm{G} 9 \mathrm{a}$ overexpression during cocaine SA led to lasting and selective changes in sensitivity to stress.

Given that these findings are opposite to attenuation of cocaine reward in naive animals tested in CPP (Maze et al., 2010), it is possible that G9a-regulated gene transcription acts differently in animals that have already self-administered cocaine for 4 weeks before the HSV-G9a infusions in the NAcSh. In Experiment 1, the effects of G9a expression are tested after 15-20 d of Cocaine self-administration (CSA), a time period when endogenous G9a levels had already decreased (Maze et al., 2010). Therefore, G9a overexpression reversed these decreases, possibly beyond baseline G9a activity levels. However, given the potential for long-term effects shown above, we tested whether limiting G9a overexpression to the initial acquisition/training phase of cocaine SA would produce similar effects on cocaine SA and relapse behaviors. Due to the transient nature of HSV overexpression ( $\sim 5 \mathrm{~d})$, rats were given 3 weekly HSV-GFP or HSVG9a infusions $1 \mathrm{~d}$ before the initial $5 \mathrm{~d}$ of cocaine $\mathrm{SA}$ and additional HSV infusions $1 \mathrm{~d}$ before weeks 2 (days 5-10) and 3 (days 11-15) of cocaine SA, similar to previously published results (Bachtell et al., 2008; Taniguchi et al., 2017; Figure 4a). G9a overexpression had no direct effect on acquisition of overall cocaine intake during the overexpression period (Fig. $4 b$, vector: $F_{(1,11)}=0.02123$, $p=0.8868$; time: $F_{(14,154)}=0.9786, p=0.4778$; interaction: $F_{(14,154)}=$ $0.5612, p=0.8915)$. Closer inspection of cocaine $\mathrm{SA}$ response patterns in individual rats showed similar mean inter-reinforcement intervals between treatment groups on the last day of cocaine SA (day 15, Fig. $4 c$, left, $t_{(11)}=0.2641, p=0.3983$ ), but rats overexpressing G9a exhibited markedly greater variance in the timing of self-injections, as indicated by the SD of the interreinforcement intervals (Fig. $4 c$, right, $F_{(6)}=23.95, p=0.0031$ ), a measure of compulsive cocaine taking (Wise and Koob, 2014). Further evidence for compulsive-like behavior is reflected by greater responding on the active lever during the $15 \mathrm{~s}$ timeout periods after each self-injection (Fig. $4 d$, left, $t_{(11)}=1.933, p=0.0397$ ). No difference in inactive lever presses were observed, indicating that increased timeout responding is not due to a generalized increase in lever pressing (Fig. $4 d$, right, $t_{(11)}=0.5303, p=0.3032$ ). Representative response patterns for GFP- and G9a-expressing rats that selfadministered an equivalent number of cocaine injections are shown in Figure $4 e$. Note the stable cocaine SA response pattern in the GFP-expressing animal compared with erratic bouts and bursts of SA in the G9a-expressing animal. Therefore, whereas G9a overexpression fails to alter overall cocaine intake during initial acquisition and maintenance of cocaine SA, the compulsive-like SA patterns suggest a loss of normal inhibitory regulation of cocaine-taking behavior.

Interestingly, when G9a overexpression was limited to the initial $15 \mathrm{~d}$ of cocaine SA, it led to similar, if not greater, increases in cocaine SA on both fixed and progressive ratio tests as produced by direct G9a overexpression during these tests. Therefore, animals with prior G9a expression showed a leftward shift in the inverted U-shaped dose-response for cocaine SA on a FR reinforcement schedule (Fig. $4 f$, vector: $F_{(1,11)}=3.443, p=0.0002$; dose: $F_{(4,44)}=13.9, p<0.0001$; interaction: $F_{(4,44)}=3.436, p=$ $0.0158)$ and also increased motivation for cocaine SA on the PR schedule (Fig. $4 g$, vector: $F_{(1,11)}=5.262, p=0.0425$; dose: $F_{(4,44)}=$ $8.237, p=0.0152$; interaction: $\left.F_{(1,11)}=2.501, p=0.1421\right)$. Due to concerns that the number of infusions may lead to differences in transgene expression, we compared the effects of one versus three HSV infusions on GFP expression and tissue damage using a within-subject design. Although there may be somewhat greater tissue damage with repeated HSV infusions (Fig. 4h), there was no major difference in GFP expression patterns after ether one or three HSV infusions (Fig. 4i). These results indicate that the increase in cocaine SA behaviors by G9a is not related to the level of drug experience before G9a modulation and that the effects of G9a on cocaine SA clearly differ from its effect on cocaine CPP.

We also tested extinction and reinstatement behaviors in these animals 6-7 weeks after the last HSV infusion and found results 
a

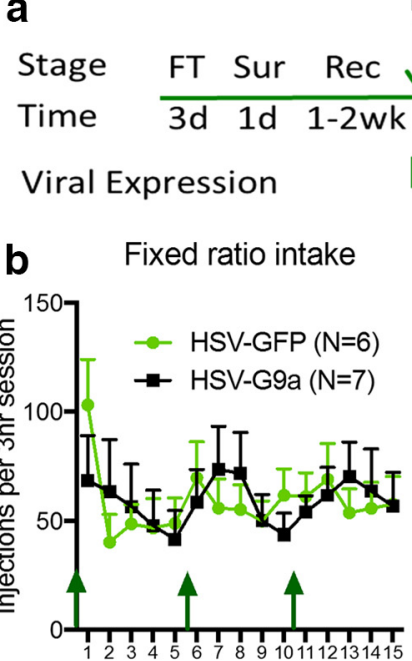

Day of fixed ratio responding

\begin{tabular}{|l|l|l|l|}
\hline eroup & IN & IRI & SD \\
\hline HSV-GFP & 83 & 1.7 & 0.6 \\
\hline HSV-G9a & 83 & 1.6 & 1.4 \\
\hline
\end{tabular}

f Post-HSV dose response

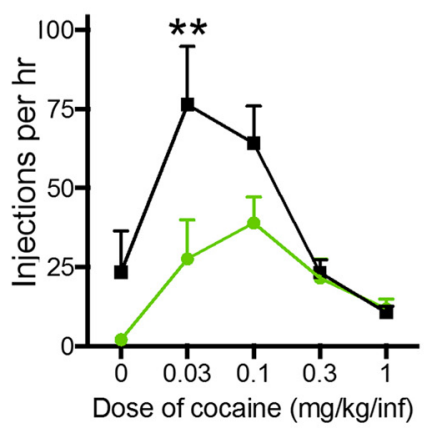

HSV infusions

Reinstatement

Reinstatement

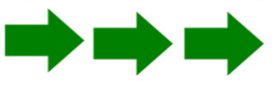

C

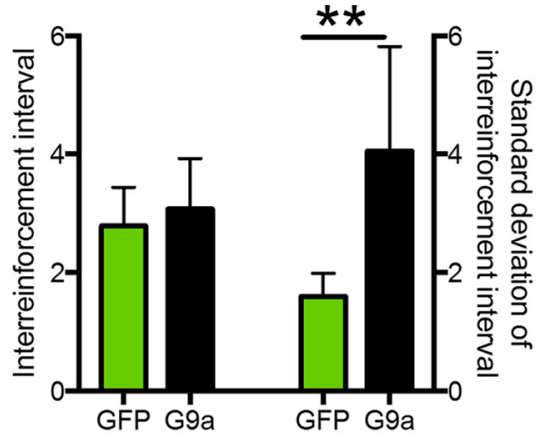

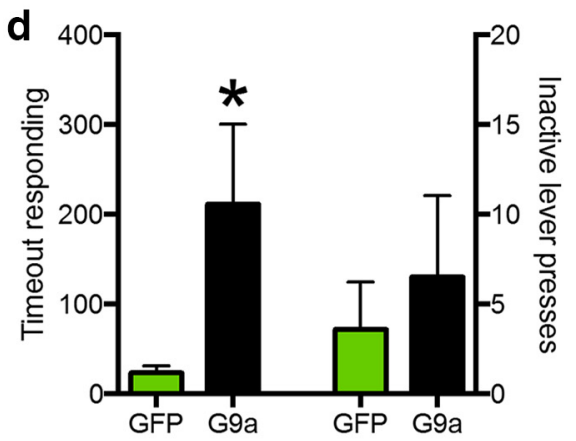

Cocaine injections during final 3 hour FR session on day 15

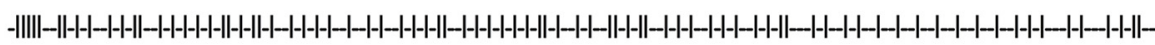
\begin{tabular}{llll}
\hline h & h & Sh
\end{tabular}

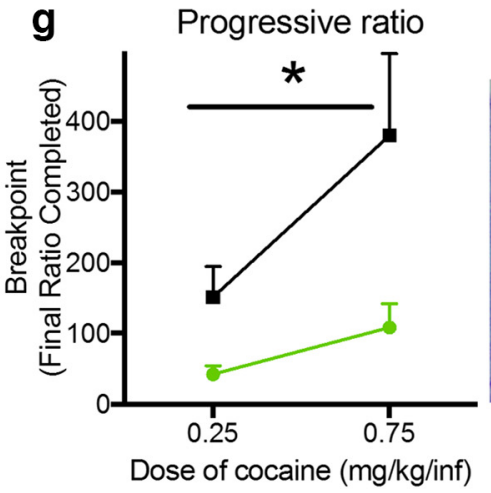

h 1 X vs $3 \mathrm{XHSV}$

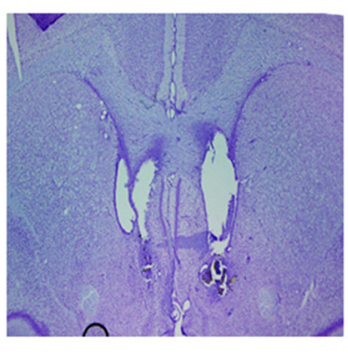

i 1 X vs $3 \times$ HSV

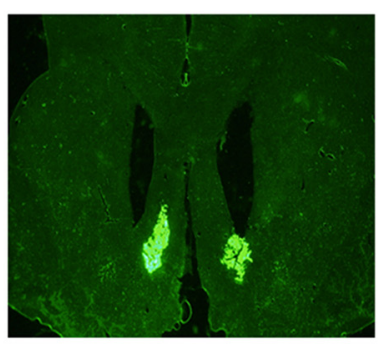

Figure 4. G9a overexpression during only the acquisition/stabilization phase leads to increased compulsivity and lasting increases in cocaine SA behaviors. $\boldsymbol{a}$, Experimental time course depicting operant training with food pellets, surgery, recovery, and FR cocaine SA acquisition training, followed by PR and dose-response testing. After a 2-week abstinence period, rats also experienced extinction training and 3 reinstatement tests: cue-induced, cocaine-induced, and after 30 min of foot-shock stress. Rats were then tested in the EPM and open-field test (OFT) before tissue collection (TC). Small green arrows represent HSV infusion times and large green arrow represents viral expression periods. $\boldsymbol{b}$, Average cocaine SA in study groups during HSV-mediated expression. $\boldsymbol{c}$, Average inter-reinforcement intervals (left) and SDs of the intervals (right) on the last day of cocaine SA training (day 15). ${ }^{* *} p<0.01$ for an Ftest compared with HSV-GFP. $d$, Timeout responding (left) and inactive lever presses (right) for rats on the last $2 \mathrm{~d}$ of cocaine SA during HSV expression. $e$, Representative traces of cocaine SA behavior (vertical traces) for an HSV-GFP and HSV-G9a rat on day 15 over the $3 \mathrm{~h}$ session. $\boldsymbol{f}$, Average cocaine SA (FR5) in study groups during dose-response testing. ${ }^{* *} p<0.01$ compared with HSV-GFP. $\boldsymbol{g}$, Cocaine SA on a PR schedule after GFP or G9a expression during prior acquisition/stabilization of cocaine SA. $\boldsymbol{h}$, Nissl stain showing tissue damage from either 1 (left) or 3 infusions (right) of HSV-GFP. $\boldsymbol{i}$, Expression of GFP after either 1 (left) or 3 infusions (right) of HSV. ${ }^{*} p<0.05$ for a significant main effect of group. Data are expressed as mean \pm SEM. HSV-GFP: $n=6$, HSV-G9a: $n=7$.

similar to the previous experiment (Fig. 3). Therefore, whereas there was no effect on cocaine-seeking behavior during extinction testing (Fig. $5 a$, vector: $F_{(1,9)}=0.7565, p=0.4070$; time: $F_{(4,36)}=6.372, p=0.0006$; interaction: $F_{(4,36)}=0.5557, p=$ 0.6961 ), cue-induced reinstatement (Fig. $5 b, t_{(8)}=0.3679, p=$ $0.3612,1 \mathrm{G} 9 \mathrm{a}$ rat did not reinstate), or cocaine-induced reinstatement (Fig. $5 c$, vector: $F_{(1,14)}=0.001323, p=0.9715$; dose: $F_{(2,28)}=$ $4.368, p=0.0223$; interaction: $F_{(2,28)}=0.2579, p=0.7746$; $1 \mathrm{G} 9 \mathrm{a}$ and 1 GFP rat did not reinstate) compared with animals with prior HSV-GFP infusions in the NAcSh, foot-shock stress-induced reinstatement was increased in animals with prior G9a overexpression (Fig. $5 d, t_{(6)}=2.952, p=0.0128,1$ GFP and 2 G9a rats did not reinstate).

Sseveral observations indicate that animals receiving intra-
NAcSh HSV-G9a infusions exhibited profound anxiety-like behavior both during G9a overexpression and long after G9a overexpression declined. First, unblinded measures found that G9a overexpression during both cocaine SA experiments led to an increase in porphyrin staining, diarrhea, biting, scratching, and excessive locomotion. These measures approached statistical significance in Experiment 1 with $2 \mathrm{HSV}$ infusions (Fig. $6 a$, left, $\left.t_{(16)}=1.596, p=0.0650\right)$ and became more prolific in Experiment 2 with 3 HSV-G9a infusions (Fig. $6 a$, right, $t_{(11)}=1.875$, $p=0.0438$ ). In Experiment 2, cocaine SA, extinction, and reinstatement testing were followed by more objective measures of anxiety, the EPM and open-field tests (Handley and Mithani, 1984). Animals receiving HSV-G9a infusions during acquisition/ stabilization of cocaine SA (last HSV infusion 7 weeks prior) 

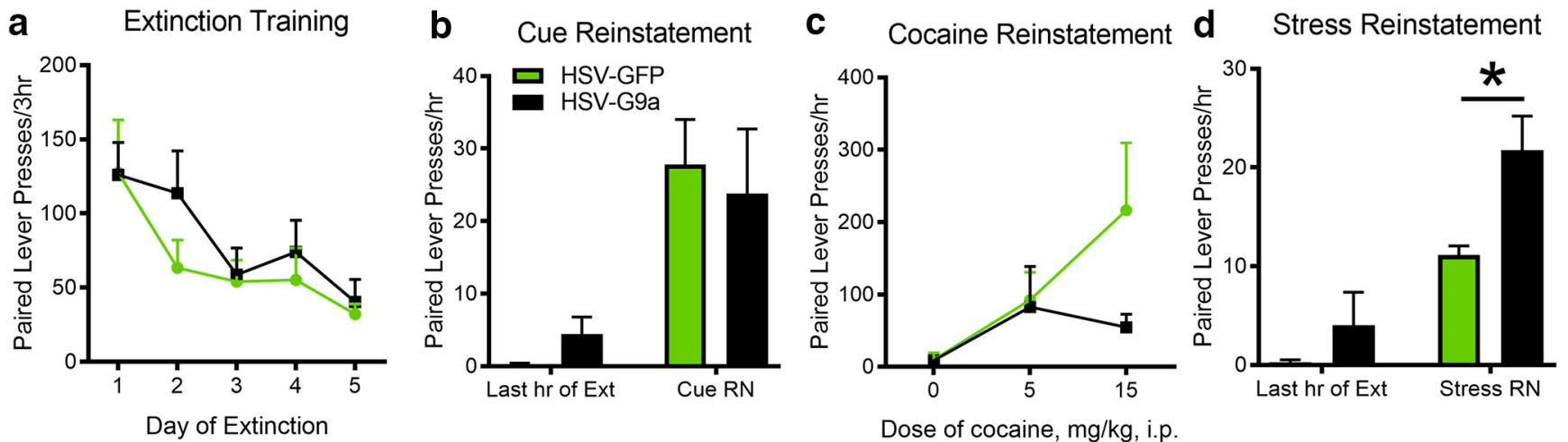

Figure 5. G9a overexpression during only the acquisition/stabilization phase leads to selective increases in foot-shock stress-induced reinstatement. Shown are paired lever presses over $5 \mathrm{~d}$ of extinction (HSV-GFP: $n=5$, HSV-G9a: $n=6 ; \boldsymbol{a}$ ), after noncontingent light and sound cue presentation (HSV-GFP: $n=5$, HSV-G9a: $n=5 ; \boldsymbol{b}$ ), after intraperitoneal injections of saline or cocaine (HSV-GFP: $n=4$, HSV-G9a: $n=5 ; \boldsymbol{c}$ ), or after intermittent foot shocks for 30 min (HSV-GFP: $n=4$, HSV-G9a: $n=4 ; \boldsymbol{d}$ ). Data are expressed as mean \pm SEM. ${ }^{*} p<0.05$ compared with HSV-GFP.

a Stress symptoms during expression

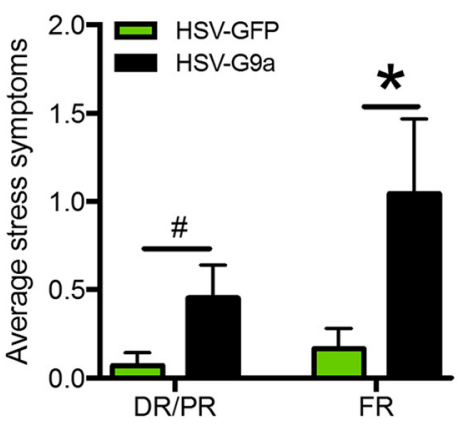

Timing of HSV Expression during SA

\section{d}

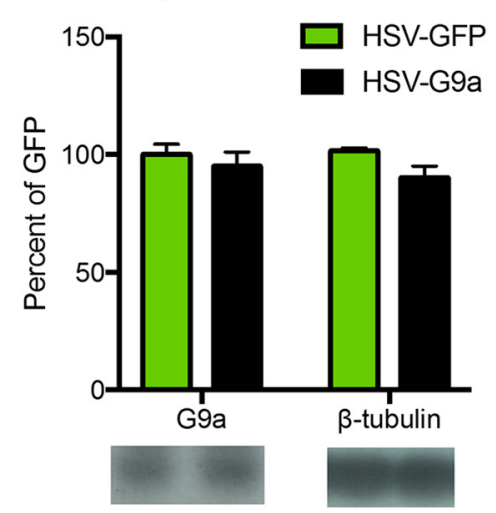

b

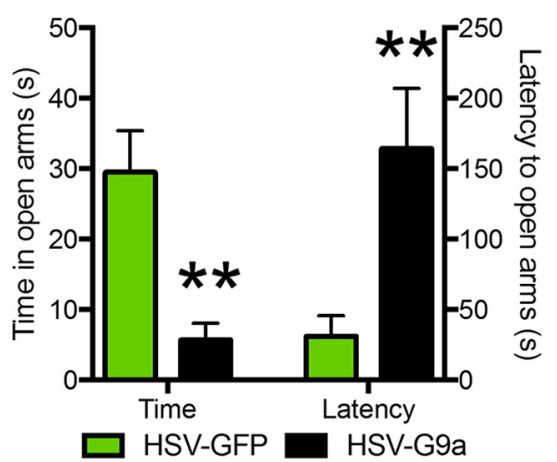

$\mathbf{e}$

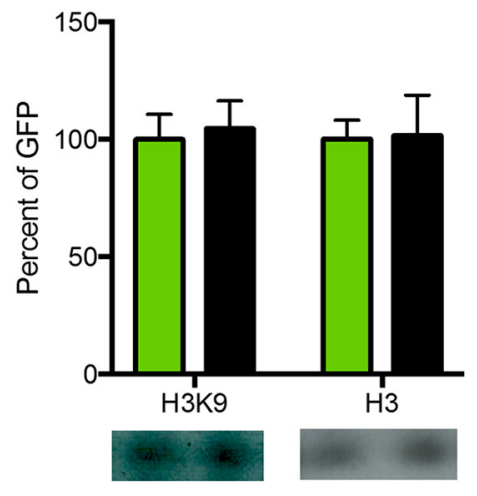

C

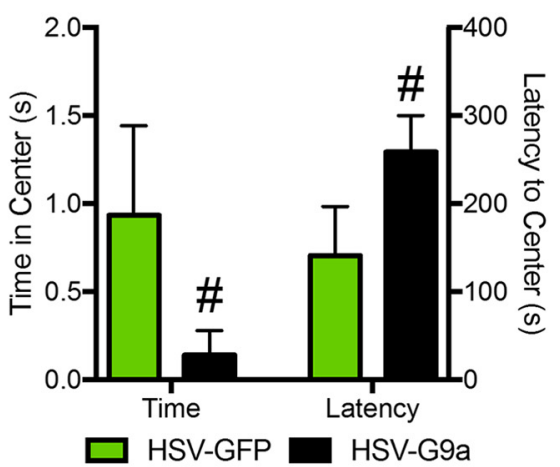

f

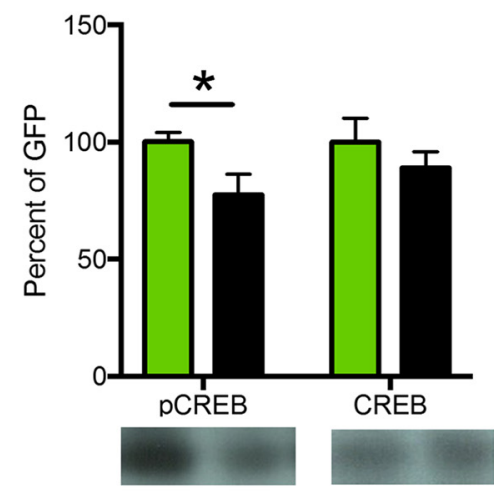

Figure 6. G9a overexpression during cocaine SA leads to lasting increases in anxiety-like behaviors and decreases in phosphorylated CREB in the NAcSh. $a$, Anxiety-like behaviors scored in animals self-administering cocaine with HSV expression during FR dose-response (DR) and PR (Experiment 1), HSV-GFP: $n=7$, HSV-G9a: $n=11$, and HSV expression during initial $15 \mathrm{~d}$ of cocaine SA (Experiment 2), HSV-GFP: $n=6$, HSV-G9a: $n=7 . \boldsymbol{b}$, Time spent in the open arms and latency to enter the open arms in the EPM test in animals completing Experiment 2. $\boldsymbol{c}$, Time spent in the center and latency to the center in the open field test (HSV-GFP: $n=5$, HSV-G9a: $n=6$ ). $\boldsymbol{d}$ - $\boldsymbol{f}$, Western blot results from NAcSh tissue after final behavioral tests for G9a (d), $\beta$-tubulin (e), H3K9me2, Histone H3 total and phosphorylated and total CREB levels ( $\boldsymbol{f}$ ) (HSV-GFP: $n=5$, HSV-G9a: $n=5$ ). Data are expressed as mean \pm SEM. \#p $<0.10,{ }^{*} p<0.05$, and ${ }^{* *} p<0.01$ compared with HSV-GFP controls.

spent less time in open arms of the EPM than animals receiving prior HSV-GFP infusions (Fig. $6 b$, left, $t_{(9)}=4.006, p=0.0015$ ) and showed a longer latency to enter the open arms of the maze (Fig. $6 b$, right, $t_{(9)}=3.568, p=0.0030$ ), consistent with an increase in anxiety. Similarly, HSV-G9a-infused animals exhibit trends for decreased time spent in the center of an open field (Fig. $6 c$, left, $\left.t_{(9)}=1.651, p=0.0665\right)$ and increased latency to enter the center region (Fig. $6 c$, right, $t_{(9)}=1.724, p=0.0594$ ). No differ- ences in distance traveled were observed in the EPM tests (GFP $=$ $\left.1312 \pm 66 \mathrm{~cm} ; \mathrm{G} 9 \mathrm{a}=1346 \pm 114 \mathrm{~cm} ; t_{(9)}=0.2421, p=0.8141\right)$ and open-field tests $(\mathrm{GFP}=2831 \pm 532 \mathrm{~cm}$; G9a $=3085 \pm 322$; $\left.t_{(9)}=0.425, p=0.3404\right)$. These results confirm that G9a overexpression in the NAcSh leads to an enduring anxiogenic state that may contribute to the increases in cocaine SA and stress-induced reinstatement (Dilleen et al., 2012).

Because G9a overexpression had lasting effects on cocaine SA, 
stress-induced reinstatement, and anxiety behaviors, we analyzed NAcSh tissue from rats in Experiment 2 for biochemical markers of G9a expression and its downstream regulation of $\mathrm{H} 3 \mathrm{~K} 9 \mathrm{me} 2$ and CREB phosphorylation. As referenced above, HSV-mediated expression is transient and there is no evidence for elevated G9a levels (Fig. $6 d, t_{(8)}=1.17, p=0.2757$ ) or H3K9me2 (Fig. $6 e, t_{(8)}=$ $0.2926, p=0.7773$ ) in NAcSh over 7 weeks after the final HSV infusion. Surprisingly, however, we found a reduction in phosphorylated CREB levels in NAcSh tissue from animals receiving prior HSV-G9a infusions compared with GFP controls (Fig. $6 f$, left, $\left.t_{(8)}=2.348, p=0.0468\right)$, whereas total CREB levels were unchanged (Fig. $6 f$, right, $t_{(8)}=0.904, p=0.3924$ ). Therefore, transient epigenetic repression by G9a overexpression leads to a long-lasting reduction in activated CREB in NAcSh.

\section{Discussion}

In this study, we found that overexpression of the histone dimethyltransferase G9a in the NAcSh increased sensitivity to cocaine reinforcement in rats self-administering cocaine under relatively free access (FR) conditions. Under more demanding PR conditions, G9a enhanced the motivation for cocaine directly as rats exerted greater effort to maintain SA. Similarly, transient gain of G9a function during cocaine SA led to a long-lasting enhancement in stress-induced reinstatement of cocaine-seeking behavior while leaving context-induced (extinction), cue-induced, or cocaine-induced reinstatement of cocaine seeking unaltered. In the case of cocaine SA, these addiction-promoting behavioral changes were evident both during and after G9a overexpression and effects on stress-induced reinstatement persisted for weeks after G9a overexpression occurred. These results suggest that even transient G9a-mediated $\mathrm{H} 3 \mathrm{~K} 9 \mathrm{me} 2$ and ensuing suppression of transcriptional activity leads to prolonged changes in NAcSh neurons that facilitate cocaine addiction.

\section{Opposite effects of G9a on CSA versus CPP}

Previous work found that G9a overexpression in the NAc decreases cocaine CPP in mice (Maze et al., 2010), in apparent contradiction to enhanced cocaine reward in cocaine SA rats in our study. It is unlikely that species differences could account for this CPP/SA discrepancy because opposite modulation of these behaviors is often encountered. For example, viral-mediated overexpression of CREB in the NAcSh suppresses cocaine CPP, instead producing a conditioned place aversion to cocaine in rats (Carlezon et al., 1998). However, we found that the exact same CREB manipulation in NAcSh increases cocaine reinforcement in rats that self-administer cocaine (Larson et al., 2011). In this case, the discrepancy between CPP and SA may reflect the negative effects of CREB on mood (Pliakas et al., 2001). Therefore, the ability to alleviate the dysphoric/depressive effects of increased CREB signaling through voluntary cocaine SA may contribute to enhanced motivation for cocaine through negative reinforcement mechanisms. Another example of a cocaine CPP/SA dichotomy involves overexpression of phospholipase $C \gamma 1$ in the NAc, which increases cocaine CPP (Bolaños et al., 2003) but decreases motivation for cocaine in progressive ratio SA tests (Anderson et al., 2017). Environmental enrichment also affects cocaine CPP and SA differentially because enriched animals have both increased CPP and decreased cocaine SA compared with control animals in standard housing (Green et al., 2010). Numerous differences exist between cocaine CPP and SA including: (1) acute versus chronic cocaine exposure, (2) intraperitoneal versus intravenous cocaine injections, (3) experimenter versus volitional cocaine administration, and (4) classical versus oper- ant conditioning. Although it is unclear which, if any, of these differences account for discrepant CPP/SA behavioral outcomes, these studies clearly illustrate the importance of conducting SA work to more fully understand the role of neurobiological changes in addiction.

Chronic, but not acute, cocaine exposure decreases levels of G9a protein and H3K9me2 in the NAc (Maze et al., 2010), a finding that could explain differences in G9a modulation of cocaine CPP versus SA. Therefore, G9a overexpression in cocaine CPP experiments would augment basal H3K9me2-mediated gene suppression, whereas G9a overexpression in cocaine SA experiments would also act to prevent or reverse cocaine-regulated expression of genes under $\mathrm{H} 3 \mathrm{~K} 9 \mathrm{me} 2$ control, leaving other chronic cocaine-regulated gene expression changes unabated. In this regard, the transcriptional profile would differ substantially between acute and chronic cocaine in CPP and SA experiments, respectively. Cocaine-induced suppression of G9a acts to release an epigenetic break of certain genes under the control of the transcription factor CREB, including BDNF (Maze et al., 2010; Covington et al., 2011), but both CREB and BDNF promote addictive behavior in cocaine SA rats (Larson et al., 2011). However, G9a also may suppress certain counteradaptive genes, thereby precluding their ability to reduce addictive behavior. Further work is needed to identify genes suppressed by G9a during cocaine SA that otherwise would counteract addictive behavior because they clearly represent important targets that convey resistance to cocaine addiction.

\section{G9a and anxiety}

The ability of G9a overexpression in the NAc to induce a generalized anxiety phenotype has not been reported previously and G9a actually facilitates resilience to chronic social defeat stress (Covington et al., 2011). We noted and scored signs of stress during both cocaine SA experiments and found anxiety-like behavior in EPM testing long after transient G9a overexpression declined, but concurrent with enhanced stress-induced reinstatement of cocaine seeking. This persistent anxiogenic state could account for increases in cocaine SA because premorbid highanxiety phenotypes predict increased cocaine SA in rats (Dilleen et al., 2012) and anxiolytics reduce cocaine SA (Augier et al., 2012). Because the altered stress/anxiety responses are evident in the absence of cocaine (stress-primed reinstatement, EPM, and open field), a higher basal anxiety state is indicated by these data. In contrast, increases in the anxiogenic effects of cocaine itself generally repress cocaine SA behavior (Maier et al., 2008). Therefore, the increases in volitional cocaine SA on the PR schedule is perhaps more consistent with an underlying anxiety state and not cocaine-induced anxiety per se. A loss of control over cocaine SA is consistent with the finding that G9a overexpression disrupted the stability of cocaine SA response patterns, including persistent lever pressing during the postinjection pause (timeout) in cocaine availability and erratic burst-like patterns of cocaine intake. This pattern of cocaine SA is thought to reflect compulsive cocaine SA (Wise and Koob, 2014) and is consistent with anxiety-addiction comorbidity in humans (Ersche et al., 2012; Jakuszkowiak-Wojten et al., 2015; Voon and Dalley, 2016). Therefore, it is possible that the enduring anxiogenic effects of G9a overexpression in NAcSh contribute strongly to increased cocaine SA and relapse behaviors in our study.

The long-term effects of G9a overexpression on cocaine SA, stress-induced reinstatement, and anxiety behavior suggest that certain neurobiological changes persist in NAcSh neurons. However, we found no enduring changes in G9a levels or in global 
levels of H3K9me2, although further work is needed to assess whether long-lasting increases in $\mathrm{H} 3 \mathrm{~K} 9 \mathrm{me} 2$ persist at a subset of target genes. Interestingly, we observed a persistent decrease in CREB phosphorylation indicative of reduced CREB activity. G9a reduces a positive feedback cycle of CREB-BDNF-TrkB-CREB signaling by inhibiting transcription of BDNF mRNA (Zhang et al., 2014) and reduced CREB activity is functionally linked to increased anxiety in rats (Barrot et al., 2005; Wallace et al., 2009; Green et al., 2010). However, the repressive actions of G9a (Zhang et al., 2014) and reduced CREB activity (Larson et al., 2011) on BDNF levels would likely not contribute to this effect because knock-down of BDNF-TrkB activity in NAc attenuates depressionand anxiety-like behaviors that occur after chronic social defeat stress (Berton et al., 2006). Together, these findings indicate that even transient G9a overexpression in NAcSh neurons can produce an enduring break on CREB activity long after the direct epigenetic repression of CREB-regulated transcription and they suggest a compelling mechanism of action for G9a to induce an enduring anxiogenic state.

Our results also suggest a common role for G9a in comorbid anxiety and substance use disorders (Vorspan et al., 2015). However, because cocaine use itself often increases anxiety (Morton, 1999; Wenzel et al., 2014), and anxiety exacerbates addictive behavior, as discussed above, the causal interaction between these behavioral phenomena is obscured by a chicken-or-egg conundrum. It is possible that individuals with high basal G9a activity in NAcSh would suffer from premorbid anxiety and thus would be more likely to develop addictive behavior with cocaine use. Similarly, individuals who are resistant to cocaine-induced reductions in G9a may be more likely to develop comorbid anxiety with cocaine addiction. Conversely, a greater sensitivity to cocaineinduced increases in at least some gene targets that are normally suppressed by G9a may convey protection for both addiction and anxiety.

\section{Future directions}

The surprising finding that overexpression of G9a in the NAcSh leads to lasting increases in both anxiety- and addiction-like behaviors illustrates the complexity of epigenetic regulation of gene transcription and its impact on complex behavior. For instance, whereas decreases in CREB phosphorylation can account for the prolonged anxiogenic effect of G9a, decreased CREB activity cannot account for increased cocaine sensitivity and motivation for cocaine in self-administering animals because reductions in NAcSh CREB levels produce the opposite effect on these behaviors (Larson et al., 2011). Therefore, it is likely that other G9aregulated transcriptional events contribute to changes in cocaine SA behavior. Ultimately, a clear delineation of the transcriptional profile underlying either anxiety or cocaine SA changes is required to fully understand the complex interaction of epigenetic factors with chronic cocaine use.

\section{References}

Anderson EM, Wissman AM, Chemplanikal J, Buzin N, Guzman D, Larson EB, Neve RL, Nestler EJ, Cowan CW, Self DW (2017) BDNF-TrkB controls cocaine-induced dendritic spines in rodent nucleus accumbens dissociated from increases in addictive behaviors. Proc Natl Acad Sci U S A 114:9469-9474. CrossRef Medline

Augier E, Vouillac C, Ahmed SH (2012) Diazepam promotes choice of abstinence in cocaine self-administering rats. Addict Biol 17:378-391. CrossRef Medline

Bachtell RK, Choi KH, Simmons DL, Falcon E, Monteggia LM, Neve RL, Self DW (2008) Role of GluR1 expression in nucleus accumbens neurons in cocaine sensitization and cocaine-seeking behavior. Eur J Neurosci 27: 2229-2240. CrossRef Medline
Back SE, Brady KT (2008) Anxiety disorders with comorbid substance use disorders: diagnostic and treatment considerations. Psychiatr Ann 38: 724-729. CrossRef Medline

Barrot M, Wallace DL, Bolaños CA, Graham DL, Perrotti LI, Neve RL, Chambliss H, Yin JC, Nestler EJ (2005) Regulation of anxiety and initiation of sexual behavior by CREB in the nucleus accumbens. Proc Natl Acad Sci U S A 102:8357-8362. CrossRef Medline

Berton O, McClung CA, Dileone RJ, Krishnan V, Renthal W, Russo SJ, Graham D, Tsankova NM, Bolaños CA, Rios M, Monteggia LM, Self DW, Nestler EJ (2006) Essential role of BDNF in the mesolimbic dopamine pathway in social defeat stress. Science 311:864-868. CrossRef Medline

Bolaños CA, Perrotti LI, Edwards S, Eisch AJ, Barrot M, Olson VG, Russell DS, Neve RL, Nestler EJ (2003) Phospholipase Cgamma in distinct regions of the ventral tegmental area differentially modulates mood-related behaviors. J Neurosci 23:7569-7576. Medline

Carlezon WA Jr, Thome J, Olson VG, Lane-Ladd SB, Brodkin ES, Hiroi N, Duman RS, Neve RL, Nestler EJ (1998) Regulation of cocaine reward by CREB. Science 282:2272-2275. CrossRef Medline

Carlezon WA Jr, Duman RS, Nestler EJ (2005) The many faces of CREB. Trends Neurosci 28:436-445. CrossRef Medline

Covington HE 3rd, Maze I, Sun H, Bomze HM, DeMaio KD, Wu EY, Dietz DM, Lobo MK, Ghose S, Mouzon E, Neve RL, Tamminga CA, Nestler EJ (2011) A role for repressive histone methylation in cocaine-induced vulnerability to stress. Neuron 71:656-670. CrossRef Medline

Dennis ML, Foss MA, Scott CK (2007) An eight-year perspective on the relationship between the duration of abstinence and other aspects of recovery. Eval Rev 31:585-612. CrossRef Medline

Dilleen R, Pelloux Y, Mar AC, Molander A, Robbins TW, Everitt BJ, Dalley JW, Belin D (2012) High anxiety is a predisposing endophenotype for loss of control over cocaine, but not heroin, self-administration in rats. Psychopharmacology (Berl) 222:89-97. CrossRef Medline

Edwards S, Graham DL, Bachtell RK, Self DW (2007a) Region-specific tolerance to cocaine-regulated cAMP-dependent protein phosphorylation following chronic self-administration. Eur J Neurosci 25:2201-2213. CrossRef Medline

Edwards S, Whisler KN, Fuller DC, Orsulak PJ, SelfDW (2007b) Addictionrelated alterations in D1 and D2 dopamine receptor behavioral responses following chronic cocaine self-administration. Neuropsychopharmacology 32:354-366. CrossRef Medline

Edwards S, Bachtell RK, Guzman D, Whisler KN, Self DW (2011) Emergence of context-associated GluR(1) and ERK phosphorylation in the nucleus accumbens core during withdrawal from cocaine self-administration. Addict Biol 16:450-457. CrossRef Medline

Ersche KD, Turton AJ, Chamberlain SR, Müller U, Bullmore ET, Robbins TW (2012) Cognitive dysfunction and anxious-impulsive personality traits are endophenotypes for drug dependence. Am J Psychiatry 169:926-936. CrossRef Medline

Green TA, Alibhai IN, Roybal CN, Winstanley CA, Theobald DE, Birnbaum SG, Graham AR, Unterberg S, Graham DL, Vialou V, Bass CE, Terwilliger EF, Bardo MT, Nestler EJ (2010) Environmental enrichment produces a behavioral phenotype mediated by low cyclic adenosine monophosphate response element binding (CREB) activity in the nucleus accumbens. Biol Psychiatry 67:28-35. CrossRef Medline

Handley SL, Mithani S (1984) Effects of alpha-adrenoceptor agonists and antagonists in a maze-exploration model of 'fear'-motivated behaviour. Naunyn Schmiedebergs Arch Pharmacol 327:1-5. CrossRef Medline

Harkness JE, Ridgway MD (1980) Chromodacryorrhea in laboratory rats (Rattus norvegicus): etiologic considerations. Lab Anim Sci 30:841-844. Medline

Jakuszkowiak-Wojten K, Landowski J, Wiglusz MS, Cubala WJ (2015) Impulsivity in anxiety disorders: a critical review. Psychiatr Danub 27 Suppl. 1:S452-S455.

Johnson BA, Ait-Daoud N, Wang XQ, Penberthy JK, Javors MA, Seneviratne C, Liu L (2013) Topiramate for the treatment of cocaine addiction: a randomized clinical trial. JAMA Psychiatry 70:1338-1346. CrossRef Medline

Larson EB, Graham DL, Arzaga RR, Buzin N, Webb J, Green TA, Bass CE, Neve RL, Terwilliger EF, Nestler EJ, Self DW (2011) Overexpression of CREB in the nucleus accumbens shell increases cocaine reinforcement in self-administering rats. J Neurosci 31:16447-16457. CrossRef Medline

Maier EY, Ledesma RT, Seiwell AP, Duvauchelle CL (2008) Diazepam alters cocaine self-administration, but not cocaine-stimulated locomotion or 
nucleus accumbens dopamine. Pharmacol Biochem Behav 91:202-207. CrossRef Medline

Marczynski TJ, Urbancic M (1988) Animal models of chronic anxiety and "fearlessness". Brain Res Bull 21:483-490. CrossRef Medline

Martell BA, Mitchell E, Poling J, Gonsai K, Kosten TR (2005) Vaccine pharmacotherapy for the treatment of cocaine dependence. Biol Psychiatry 58:158-164. CrossRef Medline

Maze I, Covington HE 3rd, Dietz DM, LaPlant Q, Renthal W, Russo SJ, Mechanic M, Mouzon E, Neve RL, Haggarty SJ, Ren Y, Sampath SC, Hurd YL, Greengard P, Tarakhovsky A, Schaefer A, Nestler EJ (2010) Essential role of the histone methyltransferase G9a in cocaine-induced plasticity. Science 327:213-216. CrossRef Medline

Morton WA (1999) Cocaine and psychiatric symptoms. Prim Care Companion J Clin Psychiatry 1:109-113. CrossRef Medline

Neve RL, Neve KA, Nestler EJ, Carlezon WA Jr (2005) Use of herpes virus amplicon vectors to study brain disorders. Biotechniques 39:381-391. CrossRef Medline

Paxinos G, Watson C (1997) The rat brain in stereotaxic coordinates. San Diego, CA: Academic.

Penrod RD, Wells AM, Carlezon WA Jr, Cowan CW (2015) Use of adenoassociated and herpes simplex viral vectors for in vivo neuronal expression in mice. Curr Protoc Neurosci 73:4.37.1-31. CrossRef Medline

Pliakas AM, Carlson RR, Neve RL, Konradi C, Nestler EJ, Carlezon WA Jr (2001) Altered responsiveness to cocaine and increased immobility in the forced swim test associated with elevated cAMP response elementbinding protein expression in nucleus accumbens. J Neurosci 21:73977403. Medline

Richardson NR, Roberts DC (1996) Progressive ratio schedules in drug selfadministration studies in rats: a method to evaluate reinforcing efficacy. J Neurosci Methods 66:1-11. CrossRef Medline

Robison AJ, Nestler EJ (2011) Transcriptional and epigenetic mechanisms of addiction. Nat Rev Neurosci 12:623-637. CrossRef Medline

Sutton MA, Schmidt EF, Choi KH, Schad CA, Whisler K, Simmons D, Kara- nian DA, Monteggia LM, Neve RL, Self DW (2003) Extinction-induced upregulation in AMPA receptors reduces cocaine-seeking behaviour. Nature 421:70-75. CrossRef Medline

Taniguchi M, Carreira MB, Cooper YA, Bobadilla AC, Heinsbroek JA, Koike N, Larson EB, Balmuth EA, Hughes BW, Penrod RD, Kumar J, Smith LN, Guzman D, Takahashi JS, Kim TK, Kalivas PW, Self DW, Lin Y, Cowan CW (2017) HDAC5 and its target gene, Npas4, function in the nucleus accumbens to regulate cocaine-conditioned behaviors. Neuron 96:130 144.e6. CrossRef Medline

Voon V, Dalley JW (2016) Translatable and back-translatable measurement of impulsivity and compulsivity: convergent and divergent processes. Curr Top Behav Neurosci 28:53-91. CrossRef Medline

Vorspan F, Mehtelli W, Dupuy G, Bloch V, Lépine JP (2015) Anxiety and substance use disorders: co-occurrence and clinical issues. Curr Psychiatry Rep 17:4. CrossRef Medline

Wallace DL, Han MH, Graham DL, Green TA, Vialou V, Iñiguez SD, Cao JL, Kirk A, Chakravarty S, Kumar A, Krishnan V, Neve RL, Cooper DC, Bolaños CA, Barrot M, McClung CA, Nestler EJ (2009) CREB regulation of nucleus accumbens excitability mediates social isolation-induced behavioral deficits. Nat Neurosci 12:200-209. CrossRef Medline

Wenzel JM, Cotten SW, Dominguez HM, Lane JE, Shelton K, Su ZI, Ettenberg A (2014) Noradrenergic beta-receptor antagonism within the central nucleus of the amygdala or bed nucleus of the stria terminalis attenuates the negative/anxiogenic effects of cocaine. J Neurosci 34:3467-3474. CrossRef Medline

Wise RA, Koob GF (2014) The development and maintenance of drug addiction. Neuropsychopharmacology 39:254-262. CrossRef Medline

Yuan X, Devine DP (2016) The role of anxiety in vulnerability for selfinjurious behaviour: studies in a rodent model. Behav Brain Res 311:201209. CrossRef Medline

Zhang Z, Tao W, Hou YY, Wang W, Kenny PJ, Pan ZZ (2014) MeCP2 repression of G9a in regulation of pain and morphine reward. J Neurosci 34:9076-9087. CrossRef Medline 